\title{
Evaluating the Operational Efficiency of Life Insurance Companies in Taiwan- An Application of the Dynamic Network SBM Model
}

\author{
Lee Chi-Ai ${ }^{1}$, Shyu Ming-Kuang ${ }^{1}$, Chiu Yung-Ho ${ }^{1}$ \\ ${ }^{1}$ Department Economics, Soochow University. No.56, Section 1, Kueiyang Street, Chungcheng District, Taipei City 100, \\ Taiwan R.O.C. \\ Correspondence: Lee Chi-Ai, Economics, Soochow University. No.56, Section 1, Kueiyang Street, Chungcheng District, \\ Taipei City 100, Taiwan R.O.C.
}

Received: August 29, 2016

Accepted: September 12, 2016

Available online: October 8, 2016

doi:10.11114/aef.v4i1.1844

URL: http://dx.doi.org/10.11114/aef.v4i1.1844

\begin{abstract}
Using a Dynamic Network Slack-based Measurement model (Tone \& Tsutsui, 2014), this study evaluated the operational efficiency of life insurance firms in Taiwan from 2006 to 2013. In contrast to previous research, we incorporated assets and liabilities management into the model and compared them against optimal efficiency values in order to determine whether firms are earning maximizing profit while ensuring long-term solvency. The life insurance industry in Taiwan has matured. We found that market competitiveness depends on firms size and business model. Financial holdings companies and large corporations are performing strongly, while small local firms and foreign-owned firms scored poorly in technical efficiency. Economies of scale contribute to the business performance of life insurance firms. Life insurance companies that had merged with or been acquired by financial holdings firms showed notable improvement in efficiency. However, change in term efficiency is a warning signal in long-term business performance of life insurance firms. Lastly, most companies achieved optimal carry-over efficiency, indicating that they place considerable emphasis on managing assets and liabilities in order to ensure future solvency.
\end{abstract}

Keywords: life insurance company, efficiency, productivity, carry-over, dynamic network SBM DEA

\section{Introduction}

In 2014, Taiwan ranked world No. 1 in life insurance penetration (measured as the percentage of insurance premium to GDP) and No. 7 in insurance density (average expenditure on premium per person). The life insurance industry in Taiwan has matured and is fiercely competitive. Due to population ageing, life insurance policies are gradually changing to long-term annuity policies. The industry will eventually be exposed to the risk of longevity, and face the challenge of whether its statutory reserves are sufficient. Therefore, we must look beyond revenue when evaluating the business performance of the life insurance industry in Taiwan. We must consider long-term liabilities, multi-period statutory reserves, and the investment of insurance funds, in order to accurately measure cross-quarter performance and provide recommendations for sustainable operation.

Previous studies on insurance performance have focused on the revenue generated from investment of manpower and assets, with the aim of maximizing profit. The insurance industry, however, is different from other industries. Insurance companies must pursue maximizing profit while ensuring they remain solvent, and manage assets and liabilities as well as return on investment of insurance funds, in order to prevent the problem of 'interest spread loss' in long-term policies. In order to accurately study the actual performance of companies, we incorporated insurance claims (representing liabilities) as an input and return on assets as a carryover value linking to the next quarter. This enhanced the completeness of our study, as we were able to analyze ongoing solvency and recommend solutions to the difficulties facing insurance companies.

A majority of previous studies on life insurance firms in Taiwan have employed the conventional DEA model (such as Wu et al. 2007; Hu et al. 2009; Pottier, 2011; Huang \& Wu, 2001; Hao et al, 2007; Chen \& Jin, 2008; Huang \& Gao, 2010; Lu et al, 2011; Hu Jin-Li, 2012), the dynamic DEA model (Fukuyama \& Weber, 2014), or the network DEA model. As a result, decision-makers have neglected changes in the internal framework of insurance companies or failed to study business performance from a multi-dimensional, multi-period angle, making it difficult to identify problematic insurance companies (Avkiran, 2015). Therefore, we applied the dynamic network slack-based measure data 
envelopment analysis (DNSBM-DEA) model of Tone \& Tsutsui (2014) to address this research gap. We analyzed in-depth how insurance companies in Taiwan have gradually adjusted to changes in their operational environment, studying multiple divisions and performance periods in order to solve the so-called "Black Box" problem. We also considered the issue of ongoing solvency, which has been disregarded by previous studies but is the most vital performance indicator for life insurance firms. This made our efficiency assessment more complete and allowed us to distinguish whether overall efficiency was founded on policy sales or on underwriting, claims, and fund management. We also utilized dynamic analysis to study the multi-period performance of life insurance companies.

We first considered the variables of revenue, liabilities, and fund management, using technical efficiency and the total factor productivity index to evaluate the cross-sectional, multi-sectional business performance of life insurance firms in Taiwan. We then decomposed the total factor productivity index to explore changes in the life insurance market and what problems insurance firms are currently facing. We incorporated both revenue and liabilities as input variables. The inputs of sub-divisions (Sub-DMU) were insurance payments and income on premiums. Lastly, we studied fund management to address the problem of interest spread loss. We designated high/ low risk investments as intermediate goods and linked sub-divisions into a network. When studying fluctuation in asset return between two periods, we used link and carry-over values to examine the connectivity and interaction between insurance divisions and financial quarters.

Ours is the first study to employ the DNSBM-DEA model to analyze the performance of the life insurance industry in Taiwan. We found that the life insurance industry in Taiwan has experienced structural change, as it is gradually dominated by financial holding companies. Market share depends on firms size and business model. From link and carry-over values, we determined that most life insurance firms are managing their assets and liabilities appropriately, ensuring ongoing solvency.

Following the introduction in Chapter 1, we outline our literature review in Chapter 2, our methodology and variables in Chapter 3, our empirical findings in Chapter 4, and finally our conclusions in Chapter 5.

\section{Literature Review}

According to Tone \& Tsutsui (2014), the main problem in using conventional DEA models to measure the relative efficiency of the inputs/outputs of decision-making units (DMU) is that they neglect the internal structure of DMUs. To improve on this weakness, Färe et al. (2007) suggested using network DEA models to process DMUs, on the premise that they have sub-technology networks. These internal sub-technologies were considered to be a "Black Box", meaning that because researchers had no available data on how they operate, they were unable to describe or examine how inputs and intermediate products affect final outputs. Subsequently, the network DEA model proposed by Tone \& Tsutsui (2009) became known as the network slack-based model (SBM). Färe et al. (2014) incorporated static and dynamic contexts into network DEA. Although network DEA can be used to interpret the interactions between different divisions, it is not capable of interpreting the influence of multiple time periods, such as multiple years.

The Window model of Klopp (1985) and the Malmquist Index developed by Färe et al. (1994) (based on Malmquist (1953)) are examples of DEA models that consider the time factor. These models can be used to interpret cross-quarter variation in efficiency, as well as decompose the catch-up and frontier-shift effects. Tone \& Tsutsui (2009), however, stated that although these models explain the input/output of each condition, they fail to explain the carry-over activity between two conditions. Dynamic DEA was first proposed by Färe \& Grosskopf (1996) to process these internal carry-over activities. The slack-based dynamic SBM (DSBM) later developed by Tone \& Tsutsui (2010) considers multiple performance periods but still disregards the activities among multiple divisions.

Combining the network SBM of 2009 and the dynamic SBM developed in 2010, Tone \& Tsutsui (2014) built the dynamic network SBM, which accounts for multi-division, multi-period activities. Put simply, the vertical axis connects multiple divisions through the network, and the horizontal axis integrates multiple time periods using carry-over activities. This model can be used to evaluate 1) overall efficiency during the observation period; 2) dynamic variation in efficiency over different time periods; and 3) dynamic variation in efficiency between different divisions.

Fukuyama \& Weber (2014) employed a dynamic two-stage network model to analyze the business performance of commercial banks in Japan. They believed that this dynamic structure would maximize returns and minimize losses from changes in resources over time. Avkiran (2015) also used the dynamic network DEA to test the robustness of 16 foreign banks and 32 domestic banks in China after the financial reforms of 2007. Network dynamics showed that efficiency estimates reflect the interaction between different divisions and time cycles. They also tested and verified the robustness and sensitivity of weights and scale returns. Therefore, the dynamic network DEA model can be used to measure the performance of DMUs across different divisions and time periods.

Fukuyama (1997) studied changes in the productivity and efficiency of Japanese life insurance companies, based on ownership structure (mutual funds and equity) and economic conditions (growth or recession). Despite regulatory and 
management differences, mutual funds and limited companies were shown to employ the same techniques. Productivity and efficiency, however, differed when the time period covered different economic conditions and types of ownership. Cummins and $\mathrm{Zi} \mathrm{(1998)} \mathrm{employed} \mathrm{the} \mathrm{translog} \mathrm{function} \mathrm{and} \mathrm{data} \mathrm{envelopment} \mathrm{analysis} \mathrm{(DEA)} \mathrm{to} \mathrm{explore} \mathrm{and} \mathrm{compare}$ the operational efficiency of 445 U.S. life insurance firms from 1988 to 1992. Larger firms showed declining return to scale, while smaller firms showed increased return to scale. Mutual and limited insurance firms were found to have a similar level of efficiency.

Using the DEA model, Wu et al. (2007) analyzed the life and health insurance industries in Canada, particularly during the period of 1996 to 1998. They found that companies were extremely efficient in both operational and business strategy. Hu et al. (2009) employed DEA to research the business efficiency of foreign-owned and local life insurance companies in China from 1999 to 2004. They also studied the relationship between ownership structure and firm efficiency. Results showed that the mean efficiency of all firms varied periodically. Pottier (2011) found that state government regulations increased costs and reduced profit for life insurance firms. The cost efficiency of insurance firms was inversely proportional to number of life insurance firms licensed by the state government, and directly correlated with total assets, after controlling for geographic concentration and bankruptcy risk. After analyzing Indian life insurance companies using dynamic DEA, Sinha (2015) found that a major weakness of static, single-period DEA models is that they are not inter-temporally comparable. Therefore, he used the DSBM proposed by Tone and Tsutsui (2010) to evaluate the performance of 15 life insurance firms from 2005-2006 and 2011-2012. He found that link variables can be used to connect the years and create a common benchmark. Results also revealed significant fluctuations in technical efficiency over the period of observation.

Huang \& Wu (2001) employed DEA to analyze the efficiency of 27 life insurance firms in Taiwan, incorporating the Malmquist Total Factor Productivity index (Malmquist TFP index) to evaluate variation in efficiency. The input variables were internal/external personnel, business management expenses and sales remuneration. The outputs were revenue from premiums and investments, and number of branches. They found that the relative efficiency of local insurance firms was higher than that of foreign-owned firms. Hao et al. (2007) used the input-oriented DEA model to research the cumulative annual performance of Taiwanese life insurance companies from 1999 to 2005. Compared to foreign-owned firms, local companies scored better in overall efficiency. However, the efficiency of international firms gradually increased as they accumulated management experience. Chen and Jin (2008) studied the efficiency of Taiwanese life insurance firms from 2004 to 2006, after adjusting for environmental effects and statistical noise. After conducting variance analysis using the three-step approach of Fried et al. (2002), they found that increasing market share can significantly reduce inefficient debt and equity investment.

Using DEA, Huang and Gao (2010) explored the efficiency of Taiwanese life insurance firms from 1994 to 2003, incorporating quasi-fixed elements as inputs. Although efficiency was initially shown to be trending upwards, it was notably reduced after quasi-fixed elements as inputs had been added, which was consistent with the rational expectation hypothesis. $\mathrm{Lu}$ (2011) conducted variance analysis of the technical efficiency of 25 life insurance companies in Taiwan from 2003 to 2006, using meta-frontier DEA to estimate efficiency. Results showed that improving employee competency, service quality, company competitiveness and profitability contributed to increasing efficiency. Hu et al (2012) employed two-stage DEA to explore the efficiency of 29 Taiwanese insurance firms from 2005 to 2009 . The aggregate efficiency of the life insurance industry showed slight increase, with foreign-owned companies more efficient than local companies. Insurance firms that had previously operated as FHC showed higher Stage 1 efficiency, but were subsequently unable to effectively improve their profit and overall efficiency.

\section{Methodology and Index Selection}

\subsection{Methodology}

Farrell (1957) proposed a single input/output method of measuring technical efficiency; however, in reality, DMUs have composite inputs and outputs. Therefore, Charnes et al. (1978) used the CCR model to develop data envelopment analysis (DEA), which expands on the Farrell theory to measure the relative efficiency of DMUs with multiple inputs and outputs.

One limitation of conventional DEA is that it can only evaluate a single production process, neglecting the efficiency of other divisions, or sub-DMUs. Also, as company performance covers multiple time periods, it is very difficult to identify whether overall efficiency is most affected by DMUs or sub-DMUs in the production process (Homburg, 2001; Castelli et al., 2004). This oft-neglected intermediate production process is known as the black box.

In order to solve the black box problem and evaluate efficiency more accurately, researchers have gradually developed dynamic, multi-period efficiency models for DEA. Notable models are the Window analysis of Klopp (1985), the Malmquist index of Fare et al. (1994), and the dynamic DEA model of Fare and Grosskopf (1996), Kao (2008), and Tone and Tsutsui (2010). Fare and Grosskopf (2000) also developed network DEA to analyze the efficiency of 
individual departments. Tone and Tsutsui (2014) then integrated network and vertical dynamics DEA as well as slack-based measures to form DNSBM DEA.

In the DNSBM DEA model, it is assumed that a company has multiple sub-DMUs linked together into a network. One time period is linked to another through carry-over activities such as capital and technology, which become key business factors in the subsequent period. The assumptions of the model are set out below: $\mathrm{n}$ DMUs $(j=1, \cdots, n) ; \mathrm{K}$ sectors in each DMU $(k=1, \cdots, K)$; the study period is $\mathrm{T}(t=1, \cdots, T)$; the inputs and outputs of sector $\mathrm{k}$ are respectively $\mathrm{m}_{\mathrm{k}}$ and $\mathrm{r}_{\mathrm{k}}$; and the link set $(\mathrm{k}, \mathrm{h})$ between sector $\mathrm{k}$ and sector $\mathrm{h}$ is represented by $\mathrm{L}$.

We express the observed data as $\quad\left\{x_{i j k}^{t} \in R_{+}\right\} \quad\left(i=1, \cdots, m_{k} ; j=1, \cdots, n ; k=1, \cdots, K ; t=1, \cdots, T\right) \quad$ and $\left\{y_{i j k}^{t} \in R_{+}\right\}\left(i=1, \cdots, r_{k} ; j=1, \cdots, n ; k=1, \cdots, K ; t=1, \cdots, T\right)$, which are equivalent to the input resources i or the output of sector $\mathrm{k}$ for $D M U_{j}$ during time t. The link among different sectors is expressed as $\mathrm{Z},\left\{z_{i j k}^{t} \in R_{+}\right\}\left(j=1, \cdots, n ; l=1, \cdots, L_{k h} ; t=1, \cdots, T\right)$ The carry-over among different sectors in a time series is $\mathrm{Z}$, $\left\{z_{j k_{t}}^{(t, t+1)} \in R_{+}\right\} \quad\left(j=1, \cdots, n ; l=1, \cdots, L_{k} ; k=1, \cdots, K ; t=1, \cdots, T-1\right)$.

The objective function is:

(a) the objective function of overall efficiency is:

$$
\theta_{o}^{*}=\min \frac{\sum_{t=1}^{T} W^{t}\left[\sum_{k=1}^{K} w^{k}\left[1-\frac{1}{m_{k}+\text { linkin }_{k}}\left(\sum_{i=1}^{m_{k}} \frac{s_{i o k}^{t-}}{x_{i o k}^{t}}+\sum_{\left(k, h_{l}=1\right.}^{\text {linkin }_{k}} \frac{s_{o(k, h)_{l} \text { in }}^{t-}}{z_{o(k, h)_{l} \text { in }}^{t}}\right)\right]\right]}{\sum_{t=1}^{T} W^{t}\left[\sum_{k=1}^{K} w^{k}\left[1+\frac{1}{r_{k}+\text { linkout }_{k}}\left(\sum_{i=1}^{r_{k}} \frac{s_{i o k}^{t+}}{y_{\text {iok }}^{t}}+\sum_{\left(k, h_{l}=1\right.}^{\text {linkout }} \frac{s_{o(k, h)_{l} \text { out }}^{t}}{z_{o(k, h)_{l} \text { out }}^{t}}\right)\right]\right]}
$$

s.t.

$$
\begin{aligned}
& x_{o k}^{t}=X_{k}^{t} \lambda_{k}^{t}+s_{k o}^{t-} \quad(k=1 \cdot, K, t \neq \quad \cdots 1 T \quad, \quad) \\
& y_{o k}^{t}=Y_{k}^{t} \lambda_{k}^{t}-s_{k o}^{t+} \quad(k=1 \cdots, \cdot K, t \neq \cdots 1 T, \quad) \\
& Z_{\text {(kh free }}^{t} \lambda_{h}^{t}=Z_{k k \text { free }}^{t} \lambda_{k}^{t} . \quad(\forall k h, \text { frøe } \forall t, \quad) \\
& z_{o(k h \text { in }}^{t}=Z_{k k \text { in }}^{t} \lambda_{k}^{t}+s_{o k h \text { in }}^{t},\left(\text { kh i i l }=\cdot 1 \cdot, \text { linkin }_{k}\right) \\
& \left.z_{\text {o(kh jut }}^{t}=Z_{\text {kl( out })}^{t} \lambda_{k}^{t}-s_{\text {okh Qut }}^{t}\right) \quad\left((k h) \text { out }=1, \cdots, \text { linkout }_{k}\right) \\
& e \lambda_{k}^{t}=1 \quad(k=1, \cdots, K ; t=1, \cdots, T) \\
& \lambda_{k}^{t} \geq 0, \quad s_{k o}^{t-} \geq 0, \quad s_{k o}^{t+} \geq 0, \quad(\forall k, \forall t) \\
& \sum_{t=1}^{T} W^{t}=1, \sum_{k=1}^{K} w^{k}=1, W^{t} \geq 0(\forall t), w^{k} \geq 0(\forall k)
\end{aligned}
$$

In the above function, $X_{k}^{t}=\left(x_{1 k}^{t}, \cdots, x_{n k}^{t}\right) \in R^{m_{k} \times n \times T}$ and $Y_{k}^{t}=\left(y_{1 k}^{t}, \cdots, y_{n k}^{t}\right) \in R^{r_{k} \times n \times T}$ are the input matrix and output matrix, respectively; $s_{k o}^{t-}$ and $s_{k o}^{t+}$ are the slack variables of input and output, respectively; and $\lambda_{k}^{t}=\left\{\lambda_{j k}^{t}\right\} \in R_{+}^{n}$ is the weight of sector $\mathrm{k}$ in period $\mathrm{t}$, whereby $e \lambda_{k}^{t}=1$ indicates that the leading surface of production technology is constructed under the assumption of variable returns to scale. 
(b) The efficiency during period $t$ as:

b 1. The efficiency of sector $\mathrm{k}$

$$
\begin{aligned}
& \tau_{o}^{t^{*}}=\min \frac{\sum_{k=1}^{K} w^{k}\left[1-\frac{1}{m_{k}+\operatorname{linkin}_{k}}\left(\sum_{i=1}^{m_{k}} \frac{s_{i o k}^{t-}}{x_{i o k}^{t}}+\sum_{(k, h)_{l}=1}^{\text {linkin }_{k}} \frac{s_{o(k, h)_{l} \text { in }}^{t-}}{z_{o(k, h)_{l} \text { in }}^{t}}\right)\right]}{\sum_{k=1}^{K} w^{k}\left[1+\frac{1}{r_{k}+\text { linkout }_{k}}\left(\sum_{i=1}^{r_{k}} \frac{s_{i o k}^{t+}}{y_{i o k}^{t}}+\sum_{(k, h)_{l}=1}^{\text {linkout }_{k}} \frac{s_{o(k, h)_{l} \text { out }}^{t}}{z_{o(k, h)_{l} \text { out }}^{t}}\right)\right]} \\
& \delta_{o k}^{*}=\min \frac{\sum_{t=1}^{T} W^{t}\left[1-\frac{1}{m_{k}+\text { linkin }_{k}}\left(\sum_{i=1}^{m_{k}} \frac{s_{i o k}^{t-}}{x_{i o k}^{t}}+\sum_{(k, h)_{l}=1}^{\text {linkin }_{k}} \frac{s_{o(k, h)_{l} \text { in }}^{t-}}{z_{o(k, h)_{l} \text { in }}^{t}}\right)\right]}{\sum_{t=1}^{T} W^{t}\left[1+\frac{1}{r_{k}+\text { linkout }_{k}}\left(\sum_{i=1}^{r_{k}} \frac{s_{i o k}^{t+}}{y_{i o k}^{t}}+\sum_{\left(k, h_{l}=1\right.}^{\text {linkout }_{k}} \frac{s_{o(k, h)_{l} \text { out }}^{t}}{z_{o(k, h)_{l} \text { out }}^{t}}\right)\right]}
\end{aligned}
$$

b 2. During period t, the efficiency of sector $k$ can be expressed as:

$$
\rho_{o k}^{t^{*}}=\min \frac{1-\frac{1}{m_{k}+\operatorname{linkin}_{k}}\left(\sum_{i=1}^{m_{k}} \frac{s_{i o k}^{t-}}{x_{i o k}^{t}}+\sum_{(k, h)_{l}=1}^{\text {linkin }_{k}} \frac{s_{o(k, h)_{l} \text { in }}^{t-}}{z_{o(k, h)_{l} \text { in }}^{t}}\right)}{1+\frac{1}{r_{k}+\text { linkout }_{k}}\left(\sum_{i=1}^{r_{k}} \frac{s_{i o k}^{t+}}{y_{i o k}^{t}}+\sum_{(k, h)_{l}=1}^{\text {linkout }_{k}} \frac{s_{o(k, h)_{l} \text { out }}^{t}}{z_{o(k, h)_{l} \text { out }}^{t}}\right)}
$$

b 3. The allocative efficiency between the link and carry-over is:

$$
\begin{aligned}
& \omega_{(k h)}^{t}=\frac{z_{(k h)}^{t}-\mathrm{p}_{(k h)}^{t}}{\mathrm{p}_{(k h)}^{t}} \quad(h=1, \cdots, n ; k=1, \cdots, K ; t=1, \cdots, T) \\
& \varpi_{l_{k}}^{(t, t+1)}=\frac{z_{l_{k}}^{(t, t+1)}-\mathrm{p}_{l_{k}}^{(t, t+1)}}{\mathrm{p}_{l_{k}}^{(t, t+1)}} \quad(k=1, \cdots, K ; t=1, \cdots, T)
\end{aligned}
$$

In the equation, $\mathrm{p}_{(k h)}^{t}$ and $\mathrm{p}_{l_{k}}^{(t, t+1)}$ are the respective optimal values of the link and carry-over. If the value of $\omega_{(k h)}^{t}$ or $\varpi_{l_{k}}^{(t, t+1)}$ equals zero, the connection among different sectors is perfect, and the accumulation from the last term exactly meets the needs of the current term. When the value is greater than zero, then it means there is a lack of a link or carry-over namely, the connection among sectors is weak and there is little dynamic accumulation of capital from the last term exactly meets the needs of the current term.

The Malmquist index of productivity indicates the growth of TFP in a DMU, and it can be factored into the catch-up effect, the frontier-shift effect, and the catch-up effect. It refers to the improvement and attenuation of Technical Efficiency (TE) within a DMU:

$$
\begin{aligned}
& D C U=\gamma_{o k}^{t \rightarrow t+1}=\frac{\rho_{o k}^{t+1 *^{*}}\left(x_{k}^{t+1}, y_{k}^{t+1}, z_{(k h)}^{t+1}, z_{i_{k}}^{(t+1, t+2)}\right)}{\rho_{o k}^{t^{t}}\left(x_{k}^{t}, y_{k}^{t}, z_{(k h)}^{t}, z_{k_{k}}^{(t, t+1)}\right)} \\
& (t=1, \cdots, T-1 ; k=1, \cdots, K ; o=1, \cdots, n)
\end{aligned}
$$

If the result of DCU is greater than 1, then it indicates that a DMU's TE has made progress between period t and period $\mathrm{t}+1$. A result equal to 1 indicates that TE stays stable. A result less than 1 indicates that there is an attenuation of TE. The Divisional Frontier-Shift (DFS) expresses the effects brought about by the change in efficiency frontier, indicating the change of the efficiency frontier between two periods: 


$$
\begin{gathered}
D F S=\sigma_{o k}^{t \rightarrow+1}=\left[\frac{\rho_{o k}^{t}\left(x_{k}^{t+1}, y_{k}^{t+1}, z_{(k h)}^{t+1}, z_{i_{k}}^{(t+1, t+2)}\right)}{\rho_{o k}^{t}\left(x_{k}^{t}, y_{k}^{t}, z_{(k h)}^{t}, z_{i_{k}}^{(t, t+1)}\right)} \times \frac{\rho_{o k}^{t+1^{*}}\left(x_{k}^{t+1}, y_{k}^{t+1}, z_{(k h)}^{t+1}, z_{k_{k}}^{(t+1, t+2)}\right)}{\rho_{o k}^{t+t^{+}}\left(x_{k}^{t}, y_{k}^{t}, z_{(k h)}^{t}, z_{i_{k}}^{(t, t+1)}\right)}\right]^{1 / 2} \\
(t=1, \cdots, T-1 ; k=1, \cdots, K ; o=1, \cdots, n)
\end{gathered}
$$

The Malmquist index of a sector is:

$$
\mathrm{DMI}=D C U \times D F S=\mu_{o k}^{t \rightarrow t+1}=\gamma_{o k}^{t \rightarrow t+1} \sigma_{o k}^{t \rightarrow t+1}(t=1, \cdots, T-1 ; k=1, \cdots, K ; o=1, \cdots, n)
$$

The Malmquist index of all sectors is:

$$
\mathrm{OMI}=\mu_{o}=\prod_{k=1}^{K}\left(\mu_{o k}^{t \rightarrow t+1}\right)^{w_{k}} \quad(o=1, \cdots n,
$$

The accumulative Malmquist index of a sector is:

$$
\mathrm{CDMI}=\xi_{o k}^{1 \rightarrow T}=\prod_{t=1}^{T-1} \mu_{o k}^{t \rightarrow t+1} \quad(o=1, \cdots, n ; k=1, \cdots, K)
$$

The accumulative Malmquist index of all sectors is:

$$
\mathrm{COMI}=\xi_{o}^{1 \rightarrow T}=\prod_{k=1}^{K}\left(\xi_{o k}^{t \rightarrow t+1}\right)^{w_{k}} \quad(o=1, \cdots, n)
$$

\subsection{Defining Variables}

We selected 23 Taiwanese life insurance firms as samples for DNSBM. We eliminated ING Life, Manulife, Life Ins. Dept. of CTC, HSBC Life, Kuo Hua Life, and Zurich, which had either undergone mergers or showed incomplete data. The research period was eight years (2006-2013) and included 184 DMUs.

The main revenue source of insurance companies is insurance premium. At the same time, however, firms are responsible for future payments to insured parties. To remain solvent over the long-term, therefore, insurance companies must not only pay careful attention to the calculation of premium rates but also ensure that funds are properly managed.

After referencing Seiford and Zhu (1999), Liu (1994), Cummins and Zi (1998), Huang and Wu (2001), Chen and Jin-Li $\mathrm{Hu}$ (2008), and Jin et al (2012), we defined assets and number of employees as Stage 1 inputs and premium income as the output. At Stage 2, where we focused on company liabilities, input variables were defined as insurance payments and premium income. The final output, return on investment (ROI), was used to compare the efficiency of different companies. Stage 1 and Stage 2 were linked by high/low risk investments. Return on assets was defined as the carry-over activity that links one period to another. The production process is shown in Fig. 1, and the variables are set out in Tables $3.1-3.3$.

Time $\mathrm{t}$

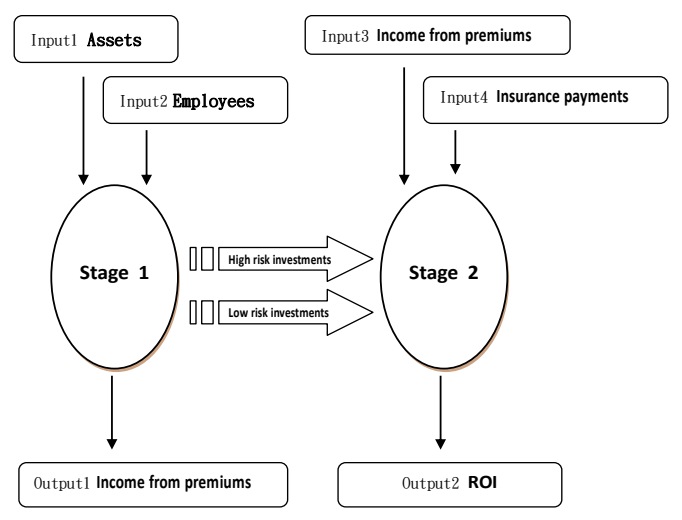

Figure 3.1 Network of Insurance Firms
Time $\mathrm{t}+1$

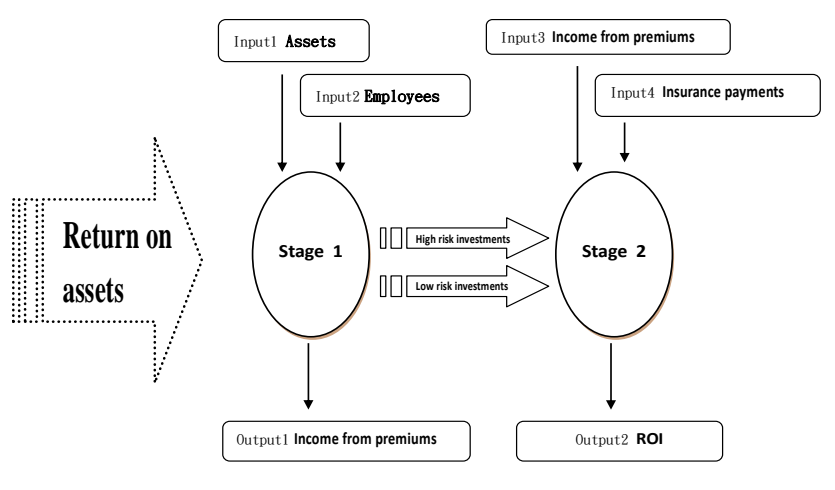


Data for variables was sourced from the Taiwan Insurance Institute and Financial Supervisory Commission. In order to offset the influence of price changes, we converted all nominal variables into real variables using the GDP deflator at 2011.

Table 3.1 Stage 1 Variables

\begin{tabular}{lccl}
\hline Variable & Full name & Unit & \multicolumn{1}{c}{ Explanation/Measurement } \\
\hline Input Variable & Assets & NT\$ thousand & Total assets in the previous quarter asappearing on the balance sheet \\
Output Variable & Employees & Individual & Internal and external staff \\
& $\begin{array}{c}\text { Insurance premium } \\
\text { received }\end{array}$ & NT\$ thousand & Price paid by consumers for insurance products products \\
\hline
\end{tabular}

Note:

1. The original date is from Taiwan Insurance Institute and the Financial Supervisory Commission.

2. Base year of consumer price index: Year $2011=100$.

Table 3.2 Stage 2 Variables

\begin{tabular}{|c|c|c|c|}
\hline Variable & Full name & Unit & Explanation/Measurement \\
\hline \multirow[t]{2}{*}{ Input Variable } & $\begin{array}{l}\text { Insurance premium } \\
\text { received }\end{array}$ & NT\$ thousand & Price paid by consumers for insurance products \\
\hline & Insurance payments & NT\$ thousand & $\begin{array}{l}\text { Payments made to insured parties in the event of } \\
\text { death or physical harm. }\end{array}$ \\
\hline Output Variable & ROI & $\%$ & $\begin{array}{l}\text { ROI }=2 \times \text { net investment income } / \text { (total assets at } \\
\text { start of quarter }+ \text { total assets at end of quarter - } \\
\text { net investment income of current quarter) } \\
\text { Net investment income }=\text { Interest income }+ \\
\text { securities income }+ \text { real estate investment } \\
\text { income }+ \text { overseas investments income }- \text { interest } \\
\text { expenses }- \text { loss on securities }- \text { loss on real estate } \\
\text { investment }- \text { loss on overseas investment }\end{array}$ \\
\hline
\end{tabular}

Note:

1. The original date is from Taiwan Insurance Institute and the Financial Supervisory Commission.

2. Base year of consumer price index: Year 2011=100.

Table 3.3. Links and Carry-over Variables

\begin{tabular}{|c|c|c|c|}
\hline Variable & Full name & Unit & Explanation/Measurement \\
\hline \multirow[t]{2}{*}{ Link } & Low risk investments & NT\$ thousand & $\begin{array}{l}\text { Total of bank deposits, government bonds, and } \\
\text { treasury bills on funds statement }\end{array}$ \\
\hline & High risk investments & NT\$ thousand & $\begin{array}{l}\text { Stocks, corporate bonds, beneficiary certificates, } \\
\text { real estate investments, and life insurance loans on } \\
\text { funds statement }\end{array}$ \\
\hline \multirow[t]{2}{*}{ Carry-over } & Return on assets & $\%$ & $\begin{array}{l}\text { Return on assets }=\text { 【After tax gain/loss }+ \text { interest } \\
\text { cost } \times(1 \text {-Expected income tax/pre-tax gain or } \\
\text { loss }) 】 \text { /average total assets }\end{array}$ \\
\hline & & & $\begin{array}{l}\text { Average total assets }=(\text { Start of quarter total assets } \\
+ \text { end of quarter total assets }) / 2\end{array}$ \\
\hline
\end{tabular}

Note:

1. The original date is from Taiwan Insurance Institute and the Financial Supervisory Commission.

2. Base year of consumer price index: Year 2011=100. 


\section{Empirical Results}

\subsection{Technical Efficiency Analysis}

As shown in Table 4.1, the Total TEs (Technical efficiency) of 65\% of life insurance firms scored lower than 0.8 . Overall, technical inefficiency was a common problem in Taiwanese insurance companies. The five companies with the highest TEs (total and term TEs equal to 1) were Taiwanese firm Cathay Life and Shin Kong Life, and international firms ACE Life Taiwan, CIGNA., and Prudential of Taiwan(Total TEs of nearly 1). Local firms Taiwan Life, Singfor Life and Bank Taiwan Life companies scored less than 0.6 for total efficiency, as did foreign-owned firms TransGlobe Life, Allianz Taiwan Life, and New York Life. However, local firms scored higher than foreign-owned corporations in aggregate efficiency.

In addition to the top five firms identified above, Chunghwa Post also performed reasonably well in Stage 1 efficiency. Prudential of Taiwan and Cardif Life had relatively good results (time-based efficiency of nearly 1) in Stage 2. Those firms that scored high in Stage 1 efficiency were all large corporations, with most small-to-medium local firms scoring low in TEs (between 0.1 and 0.7). Stage 1 TEs revealed that many firms show weak sales performance, reflecting the fact that the life insurance market in Taiwan is approaching saturation and that business development is challenging. This is particularly true for small to medium sized businesses, which face the highest levels of competitive pressure. Comparatively, insurance firms that enjoy economies of scale within these subsidiaries of FHC or large corporations have market advantage. In Stage 2, most foreign-owned corporations scored higher than local firms in the second stage, indicating that international firms are better than local firms on underwriting, claims and fund management.

Our findings from the term efficiency analysis in Table 4.2 are as follows: (1) The subprime mortgage financial crisis in 2007 significantly impacted foreign-owned firms, with companies such as TransGlobe Life, Allianz Taiwan Life, Cardif, Nan Shan Life, PCA Life, and New York Life showing a notable decline in term efficiency. However, local firms showed no meaningful fluctuation in term efficiency. (2) Life insurance companies that had merged with or been acquired by financial holdings firms showed notable improvement in efficiency. Notable examples are Metlife (which was acquired by CTBC Financial Holdings Co. Ltd in 2011); PCA Life (which was acquired by CTBC Financial Holdings Co. Ltd in 2009), and Nan Shan Life (which was acquired by Ruen Chen Investment Holdings of Taiwan in 2011). However, Merger and acquisition of foreign-owned firms and small to medium sized firms did not lead to any notable change in efficiency. Examples are TransGlobe Life (which was sold to a Taiwanese company in 2009 and merged with Kuo Hua Life in 2012) and Allianz Taiwan Life (Uni-President transferred its equity in the company to Allianz Group in 2007; in 2012, Allianz Taiwan Life merged with HSBC Life). (3) The "Go West" policy of China has not improved the business performance of small Taiwanese life insurance firms. For example, China Life established Chinese subsidiaries in 2011. However, this did not lead to any increase in efficiency.

Tables 4.1 and 4.2 reveal that the efficiency of life insurance firms is closely linked to their financial performance. As soon as companies encounter financial problems, their short-term efficiency immediately declines. A notable example is that: (1) Allianz Taiwan Life, which sold investment-type policies in 2006. Illegally raising guarantee interest rates meant that its insurance reserves were insufficient, dragging efficiency down to 0.2498 . Although its equity transferred to the Allianz Group in 2007, the long-term debt issues reduced efficiency to 0.2 the following year. Its total efficiency is only 0.3048. (2) From 2007 to 2009, Hontai Life had a term efficiency score of nearly 1. In 2010, however, the company incurred financial loss, and efficiency began a trend of decline until it was only 0.5234 by 2012. (3) Singfor Life and Global Life both suffered a government takeover in 2014 after they could not recover financially from interest spread loss and enormous gaps in net worth. Their total efficiency was 0.4247 and 0.7612 , respectively. (4) Farglory Life was penalized by the government in 2013 for failure to meet the required capital adequacy ratio. Its term efficiency value from 2012 to 2013 was less than 0.6.

The most important principle for life insurance companies is to ensure long-term solvency. Companies must be equipped with adequate long-term reserves in order to protect the interests of insured parties. We found that change in operational efficiency is a warning signal in the long-term business performance of life insurance firms. 
Table 4.1 Stage 1 Efficiency, Stage 2 Efficiency and Total Efficiency in 23 Taiwanese Life Insurance Firms

\begin{tabular}{|c|c|c|c|}
\hline \multirow{2}{*}{ DMU } & \multirow{2}{*}{ Total TE } & \multicolumn{2}{|c|}{ Divisional Efficiency } \\
\hline & & Stage 1 & Stage 2 \\
\hline MassMutual Mercuries & 0.6374 & 0.5070 & 0.8057 \\
\hline Metlife & 0.7762 & 0.8048 & 0.8570 \\
\hline ACE Life Taiwan & 1.0000 & 1.0000 & 1.0000 \\
\hline China Life & 0.7469 & 0.6720 & 0.8622 \\
\hline Chunghwa Post & 0.8660 & 1.0000 & 0.8012 \\
\hline Taiwan Life & 0.5682 & 0.4412 & 0.7151 \\
\hline TransGlobe Life & 0.5991 & 0.5451 & 0.6933 \\
\hline Allianz Taiwan Life & 0.3048 & 0.1410 & 0.7543 \\
\hline Hontai Life & 0.8430 & 0.8835 & 0.8519 \\
\hline Singfor Life & 0.4247 & 0.4173 & 0.5622 \\
\hline Cardif & 0.7851 & 0.6291 & 0.9982 \\
\hline Nan Shan Life & 0.7120 & 0.6638 & 0.7689 \\
\hline PCA Life & 0.6778 & 0.7651 & 0.8805 \\
\hline Prudential of Taiwan & 0.9830 & 0.9680 & 1.0000 \\
\hline Cathay Life & 1.0000 & 1.0000 & 1.0000 \\
\hline New York Life & 0.5376 & 0.5290 & 0.7060 \\
\hline Global Life & 0.7612 & 0.6893 & 0.9403 \\
\hline CIGNA & 1.0000 & 1.0000 & 1.0000 \\
\hline Fubon Life & 0.8382 & 0.9796 & 0.8939 \\
\hline Shin Kong Life & 1.0000 & 1.0000 & 1.0000 \\
\hline Bank Taiwan Life & 0.5363 & 0.4700 & 0.6317 \\
\hline Farglory Life & 0.7514 & 0.8165 & 0.9241 \\
\hline Sinon Life & 0.7526 & 0.7674 & 0.9214 \\
\hline
\end{tabular}

Note: Total TE (technical efficiency) is a weighted arithmetic mean of divisional scores. 
Table 4.2 Term Efficiency in 23 Taiwanese Life Insurance Firms from 2006 to 2013

\begin{tabular}{|c|c|c|c|c|c|c|c|c|c|}
\hline \multirow{2}{*}{ DMU } & \multirow{2}{*}{ Total TE } & \multicolumn{8}{|c|}{ Term Efficiency } \\
\hline & & 2006 & 2007 & 2008 & 2009 & 2010 & 2011 & 2012 & 2013 \\
\hline MassMutual Mercuries & 0.6374 & 0.7001 & 0.8213 & 0.6160 & 0.6808 & 0.5100 & 0.5649 & 0.5482 & 0.6744 \\
\hline Metlife & 0.7762 & 0.5888 & 0.6283 & 0.9997 & 0.8637 & 0.3848 & 0.9942 & 0.9990 & 1.0000 \\
\hline ACE Life Taiwan & 1.0000 & 1.0000 & 1.0000 & 1.0000 & 1.0000 & 1.0000 & 1.0000 & 1.0000 & 1.0000 \\
\hline China Life & 0.7469 & 0.7540 & 0.9081 & 0.8798 & 0.6816 & 0.6782 & 0.7971 & 0.5226 & 0.7594 \\
\hline Chunghwa Post & 0.8660 & 1.0000 & 0.8687 & 1.0000 & 1.0000 & 0.6340 & 0.7132 & 1.0000 & 0.7617 \\
\hline Taiwan Life & 0.5682 & 0.3822 & 0.5260 & 0.3477 & 0.6727 & 0.9982 & 0.7859 & 0.4534 & 0.3762 \\
\hline TransGlobe Life & 0.5991 & 1.0000 & 1.0000 & 0.5487 & 0.3460 & 0.4719 & 0.4197 & 0.5877 & 0.4748 \\
\hline Allianz Taiwan Life & 0.3048 & 0.2498 & 0.3720 & 0.2056 & 0.3232 & 0.4650 & 0.2508 & 0.3456 & 0.2684 \\
\hline Hontai Life & 0.8430 & 0.8011 & 1.0000 & 0.9991 & 1.0000 & 0.8127 & 0.7414 & 0.5234 & 0.9995 \\
\hline Singfor Life & 0.4247 & 0.4372 & 0.3940 & 0.2902 & 0.5574 & 0.4410 & 0.5159 & 0.5559 & 0.3005 \\
\hline Cardif & 0.7851 & 0.6699 & 0.6019 & 0.5702 & 0.8029 & 1.0000 & 0.9877 & 0.7218 & 0.9970 \\
\hline Nan Shan Life & 0.7120 & 0.9998 & 1.0000 & 0.4987 & 0.3472 & 0.3918 & 0.5118 & 0.9681 & 0.9992 \\
\hline PCA Life & 0.6778 & 0.4747 & 0.265 & 0.4005 & 1.0000 & 1.0000 & 1.0000 & 1.0000 & 1.0000 \\
\hline Prudential of Taiwan & 0.9830 & 0.8799 & 1.0000 & 1.0000 & 1.0000 & 0.9982 & 0.9939 & 0.9949 & 1.0000 \\
\hline Cathay Life & 1.0000 & 1.0000 & 1.0000 & 1.0000 & 1.0000 & 1.0000 & 1.0000 & 1.0000 & 1.0000 \\
\hline New York Life & 0.5376 & 0.4485 & 0.5199 & 0.4084 & 0.5223 & 0.4712 & 0.8217 & 0.9965 & 0.3690 \\
\hline Global Life & 0.7612 & 0.7495 & 0.9992 & 0.7116 & 0.7034 & 0.9916 & 0.7061 & 0.6503 & 0.6887 \\
\hline CIGNA & 1.0000 & 1.0000 & 1.0000 & 1.0000 & 1.0000 & 1.0000 & 1.0000 & 1.0000 & 1.0000 \\
\hline Fubon Life & 0.8382 & 0.6423 & 0.4769 & 1.0000 & 1.0000 & 0.9989 & 1.0000 & 0.9980 & 0.8945 \\
\hline Shin Kong Life & 1.0000 & 1.0000 & 1.0000 & 1.0000 & 1.0000 & 1.0000 & 1.0000 & 1.0000 & 1.0000 \\
\hline Bank Taiwan Life & 0.5363 & 0.3865 & 0.7028 & 0.7018 & 0.6284 & 0.5794 & 0.6170 & 0.4067 & 0.3267 \\
\hline Farglory Life & 0.7514 & 1.0000 & 0.9996 & 1.0000 & 1.0000 & 1.0000 & 0.9865 & 0.3019 & 0.5630 \\
\hline Sinon Life & 0.7526 & 0.755 & 0.4791 & 0.3246 & 1.0000 & 1.0000 & 1.0000 & 1.0000 & 1.0000 \\
\hline
\end{tabular}

Note: Total TE (technical efficiency) is a weighted arithmetic mean of divisional scores. Term Efficiency is term technical efficiency

\subsection{Efficiency of Links and Carry-overs}

Table 4.3 shows the efficiency of links and carry-overs in each firm. Divisions are linked by high and low risk investments. The four companies that achieved optimal efficiency are foreign-owned firms ACE Life Taiwan and CIGNA, and local firms Chunghwa Post and Shin Kong Life. In 83\% of firms, the sales and marketing department in Stage 1 was not adequately linked to operations divisions (underwriting, claims, and investment departments) in Stage 2. Link efficiency also shows that each company has a different investment strategy: Local firms take a more conservative approach to investment, while international firms invest more actively. Year-on-year data also shows that companies experiencing financial difficulties tended to over-invest in high risk products. These findings show that most life insurance firms need to adjust their asset allocation. Instead of over-investing in low risk products, domestic firms should allocate some funds to more profitable financial products. Foreign-owned companies should reduce their ratio of investment in high-risk products.

The carry-over mechanism between financial periods is return on assets. If financial periods are not adequately connected through carry-over activities, firms are more vulnerable to fiscal issues. Proper asset management is essential 
to the long-term operation of a life insurance company. Local firms Shin Kong Life achieved optimal efficiency, as did international firms ACE Life Taiwan and CIGNA. However, a closer study of fluctuation by quarter revealed that the reason many firms did not achieve optimal efficiency was because they failed to reach a carry-over value of 0 in a few quarters (Table 4.4). Overall, most companies achieved optimal carry-over efficiency, meaning that return on assets from the previous quarter drives business dynamics in the next quarter. This indicates that companies are managing their assets and liabilities appropriately, ensuring ongoing solvency.

Table 4.3 Efficiency of Links and Carry-overs in 23 Insurance Firms in Taiwan

Link

DMU $\begin{gathered}\text { High Risk } \\ \text { Investments }\end{gathered} \begin{gathered}\text { Low Risk } \\ \text { Investments }\end{gathered}$

\begin{tabular}{lccc}
\hline MassMutual Mercuries & -9.4900 & -10.3875 & 1.4863 \\
Metlife & -0.4200 & -15.0300 & 0.4725 \\
ACE Life Taiwan & 0.0000 & 0.0000 & 0.0000 \\
China Life & -3.8963 & -5.6000 & 0.5575 \\
Chunghwa Post & 0.0000 & 0.0000 & 0.1313 \\
Taiwan Life & -33.1663 & 66.4388 & 1.1525 \\
TransGlobe Life & -26.0038 & -32.4975 & 2.0563 \\
Allianz Taiwan Life & -23.8963 & 4.1525 & 0.4050 \\
Hontai Life & -17.6338 & 77.0863 & 0.9200 \\
Singfor Life & -27.4650 & 141.7788 & 24.4088 \\
Cardif & 0.0413 & 0.0875 & 0.0038 \\
Nan Shan Life & -20.5263 & -29.1825 & 1.2263 \\
PCA Life & 5.3850 & -24.3575 & 3.7938 \\
Prudential of Taiwan & -0.0250 & -0.2413 & 0.0038 \\
Cathay Life & -0.0163 & 0.0150 & 0.0100 \\
New York Life & -11.0500 & 0.5525 & 2.6013 \\
Global Life & -0.0500 & -0.0488 & 0.1275 \\
CIGNA & 0.0000 & 0.0000 & 0.0000 \\
Fubon Life & -1.4613 & 24.8388 & 0.3450 \\
Shin Kong Life & 0.0000 & 0.0000 & 0.0000 \\
Bank Taiwan Life & -39.3125 & -11.1238 & 2.6025 \\
Farglory Life & -8.3138 & 8.1475 & 0.0250 \\
Sinon Life & -7.2400 & 19.8763 & 0.2975 \\
\hline
\end{tabular}

Table 4.4. Number of Companies that Achieved Optimal Carry-over Term Efficiency of 23 Firms in Taiwan

\begin{tabular}{cccccccccc}
\hline Year & 2006 & 2007 & 2008 & 2009 & 2010 & 2011 & 2012 & 2013 \\
\hline $\begin{array}{l}\text { Number of firms } \\
\text { which carry-over= }\end{array}$ & in & 19 & 17 & 19 & 20 & 20 & 22 & 22 & 16 \\
\hline
\end{tabular}

\subsection{TFP Index}

We employed the Malmquist Total Factor Productivity (TFP) index to study the operational efficiency of 23 life insurance firms in Taiwan, based on the relationships between their inputs and outputs. We then further analyzed the business issues highlighted by the results.

\subsubsection{Analyzing Variation in the TFP Index}

Tables 4.5 and 4.6 show the Malmquist TFP index results for 23 life insurance firms in Taiwan between 2006 and 2013. Forty-three percent of companies showed improvement in overall TFP, particularly in Stage 1. The TFP score of local 
life insurance firms exceeds international life insurance firms, where the financial holdings companies scored the highest.

Mean TFP for all 23 firms was 1.0027 and improved in Stage 1. The TFP of local life insurance firms showed improved productivity, while the international life insurance firms showed a decline in productivity. In stage 1, 14 firms had TFP index values greater than 1 . Most of the remaining 9 companies that scored less than 1 in TFP had experienced financial problems during the period of 2006 to 2013. Stage 1 variation in TFP shows that the life insurance market in Taiwan is already saturated, and market territory has changed. Life Insurance, Personal Injury Insurance, Health Insurance, Annuity Insurance are the main insurance products sold in the Taiwanese insurance market. The main reasons for saturation are: 1. Stalled economic growth in Taiwan: With limited income, consumers struggle to afford new policies. 2. The scope of social insurance and labor pension has been expanded. As well as the implementation of national health insurance, access to basic economic and retirement security has reduced the willingness to buy commercial insurance. Large FHC and corporate groups have created economies of scale, crowding out small companies and foreign-owned firms. Unless they can develop and stimulate demand for new products, small companies and foreign-owned firms are unlikely to improve their productivity in Stage 1.

Overall TFP declined mainly due to the poor results in Stage 2. Companies performed poorly in Stage 2. In $40 \%$ of companies showed improvement particularly in TFP. Mean TFP for all 23 firms was 0.9282 and declined in Stage 2. This indicates that staff in underwriting and claims departments lack the expertise required to conduct quality reviews of policies and claims. However, an ageing population has created a 'longevity risk' in Taiwan, leading to potential future liabilities. As Baby Boomers grew into retirees, claims expenditure increased, reducing the finances available for long-term investment. If too much time is spent underwriting process and claims review, funds are not utilized or invested effectively. Companies must improve the professional knowledge and skills of employees in these areas in order to reduce unnecessary loss.

Table 4.5 Productivity Index of 23 Insurance Firms in Taiwan

\begin{tabular}{llllllll}
\hline \multirow{2}{*}{ DMU } & Overall TFP & Stage 1 & \multicolumn{5}{c}{ Stage 2} \\
& TFP & DFS & DCU & TFP & DFS & DCU \\
\hline MassMutual Mercuries & 1.0222 & 1.0064 & 1.0203 & 0.9864 & 1.0383 & 1.0353 & 1.0029 \\
Metlife & 1.0134 & 1.2057 & 1.1137 & 1.0826 & 0.8517 & 0.7923 & 1.0750 \\
ACE Life Taiwan & 0.7185 & 0.5204 & 0.5204 & 1.0000 & 0.9921 & 0.992 & 1.0000 \\
China Life & 0.9129 & 1.0232 & 1.0947 & 0.9347 & 0.8145 & 0.7918 & 1.0287 \\
Chunghwa Post & 1.0311 & 1.1429 & 1.1429 & 1.0000 & 0.9302 & 0.9966 & 0.9334 \\
Taiwan Life & 0.9234 & 1.0284 & 1.0729 & 0.9585 & 0.8291 & 0.8127 & 1.0202 \\
TransGlobe Life & 0.8464 & 0.9366 & 1.0920 & 0.8577 & 0.7648 & 0.8198 & 0.9329 \\
Allianz Taiwan Life & 0.5837 & 0.8472 & 0.9672 & 0.8759 & 0.4021 & 0.3948 & 1.0185 \\
Hontai Life & 0.8688 & 0.9956 & 0.9815 & 1.0144 & 0.7582 & 0.7203 & 1.0526 \\
Singfor Life & 0.8494 & 0.9953 & 1.0703 & 0.9300 & 0.7209 & 0.7210 & 0.9997 \\
Cardif & 0.9206 & 1.0676 & 0.9428 & 1.1324 & 0.7938 & 0.7932 & 1.0008 \\
Nan Shan Life & 1.1655 & 1.0755 & 1.0756 & 0.9999 & 1.2631 & 1.2632 & 0.9999 \\
PCA Life & 1.3795 & 1.1120 & 0.9825 & 1.1318 & 1.7113 & 1.6053 & 1.0660 \\
Prudential of Taiwan & 1.0550 & 1.0065 & 0.9688 & 1.0389 & 1.1059 & 1.1058 & 1.0002 \\
Cathay Life & 1.1823 & 1.0507 & 1.0507 & 1.0000 & 1.3304 & 1.3304 & 1.0000 \\
New York Life & 0.7745 & 0.9673 & 1.0720 & 0.9024 & 0.6202 & 0.5815 & 1.0663 \\
Global Life & 0.7768 & 0.9471 & 1.0484 & 0.9034 & 0.6371 & 0.5976 & 1.0661 \\
CIGNA & 0.9623 & 0.8541 & 0.8541 & 1.0000 & 1.0841 & 1.0841 & 1.0000 \\
Fubon Life & 1.0773 & 1.1352 & 1.1201 & 1.0135 & 1.0223 & 0.9745 & 1.0490 \\
Shin Kong Life & 0.9029 & 1.0914 & 1.0914 & 1.0000 & 0.7469 & 0.7469 & 1.0000 \\
Bank Taiwan Life & 1.0914 & 1.1250 & 1.1028 & 1.0202 & 1.0588 & 1.1313 & 0.9360 \\
Farglory Life & 1.0118 & 0.8944 & 1.0356 & 0.8636 & 1.1445 & 1.1571 & 0.9891 \\
Sinon Life & 0.8652 & 1.0278 & 0.9494 & 1.0826 & 0.7284 & 0.7278 & 1.0009 \\
Mean & 0.9537 & 1.0024 & 1.0161 & 0.9882 & 0.9282 & 0.9207 & 1.0104 \\
\hline
\end{tabular}


Table 4.6 TFP Analysis of 23 Life Insurance Firms in Taiwan

\begin{tabular}{cccc}
\hline Item & Overall TFP & Stage 1 & Stage 2 \\
\hline Improved productivity (TFP>1) & 10 firms & 14 firms & 9 firms \\
Decline in productivity (TFP<1) & 13 firm & 9 firms & 14 firms \\
\hline
\end{tabular}

4.3.2 Decomposing TFP Results in Stages 1 and 2

In $60 \%$ of companies improved TFP in Stage 1, which is the sales phase. Frontier-shift effect contributed more to this improvement than catch-up effect in Stage 1. While 65\% of firms in Stage 1 showed improvement in frontier-shift effect, only 35\% improved in catch-up effect. Mean frontier-shift effect for all 23 firms was 1.0161, and mean catch-up effect was 0.9884 (reduced). This means that despite significant improvement in professional training and sales techniques, most companies are failing to realize the full potential of their manpower and assets.

In Stage 1, four companies scored less than 1 for TFP due to financial difficulties. With the exception of Sinon Life, the other companies scored greater than 1 in frontier-shift effect but performed poorly in catch-up effect. This indicates that these companies have no problem with sales techniques or expertise; their financial loss is attributable to failing to properly utilize their manpower and funds.

International firms did not score well in TFP for Stage 1, meaning that their sales performance was poor. When we decomposed their TFP scores, we found deteriorating frontier-shift effect and stagnant catch-up effect in all firms, such as ACE Life Taiwan, Cardif Life, Prudential of Taiwan, and CIGA. Why did foreign-owned insurance firms, with their extensive histories and abundant commercial experience, show deteriorating frontier-shift effect? Because opportunity for profit in the Taiwanese market is limited, these companies are also not motivated to improve their sales techniques. Their stagnant catch-up effect also shows that they are no longer striving to improve the management of their manpower and resources. Over the past five years, foreign-owned companies have been gradually withdrawing from the fiercely competitive life insurance market in Taiwan by either divesting or selling their business to local firms.

Overall, TFP was not significantly improved in Stage 1. Catch-up effect scores showed that in a saturated market, even state-owned enterprises or large FHC have limited room for expansion. They can only hope to boost premium income by attracting new customers through new products, quality customer service, goodwill, and promotions.

The inputs at Stage 2 were premium income and insurance payments. This improved productivity reduces policy cancelation rates and strengthens liquidity, enabling the company to accumulate more reserve funds. Also, an effective investment division that manages funds and risks appropriately can increase ROI, contributing significantly to performance in Stage 2. As shown in Table 4.5, most companies performed poorly in Stage 2. TFP declined mainly due to the poor results in frontier-shift effect. Considering the catch-up effect, not much change were observed in both local life insurance firms and international life insurance firms.

The TFP scores of 9 companies were greater than 1 in the second stage. Furthermore, only $35 \%$ of firms showed advancement in frontier-shift effect (improvement of 1.03 to 1.6), with mean frontier-shift effect at 0.9207 . However, $40 \%$ of firms improved in catch-up effect (improvement of 1.01 to 1.07), with mean catch-up effect at 1.0104 . All companies that showed improvement in catch-up were privately owned enterprises. However, the TFP of most companies showed no improvement or even decline in Stage 2. This means that most firms are unable to optimize the administrative efficiency of underwriting and claims departments. Companies must improve their human resource management in Stage 2, in order to raise their TFP indices.

\section{Conclusion}

Ours is the first study to utilize the Dynamic Network Slack-based Measurement Model developed by Tone \& Tsutsui (2014) to explore the business performance of life insurance firms in Taiwan. In contrast to other studies, we employed output-oriented DEA to solve for efficiency using non-radial slack. We also incorporated carry-over, which is lacking in dynamic DEA, and analyzed the three key elements of business performance in life insurance firms: income, liabilities, and fund management.

Empirical findings have shown that compared to conventional or dynamic DEA, the DNSBM DEA model is better able to represent the actual state of a life insurance company. In Stage 1, Singfor Life and Global Life scored poorly in efficiency and showed declining rates of technical efficiency. This finding contrasts with that of Hu et al. (2012), who discovered strong efficiency rates in Stage 1 (using a two-stage DEA model). However, these companies were taken over by the government in 2014 due to severe financial difficulties.

Technical inefficiency was a common problem in Taiwanese insurance companies. Those firms that scored high in efficiency were all large corporations, with most small-to-medium local firms scoring low in TEs. Overall, local firms scored higher than foreign-owned corporations in aggregate efficiency, contrasting with the findings of Hu et al (2012). 
The TFP score of local life insurance firms also exceeds international life insurance firms, where the financial holdings companies scored the highest.

We found that the sales techniques of life insurance firms in Taiwan are mature, market competitiveness depends on firms size and business model. However, the Taiwanese insurance market is dominated by large insurance companies. Most foreign-owned and small-to-medium local firms show weak sales results and relatively limited profit margins. Due to the decline in term efficiency, those firms fall into financial crisis one after another, leading to their exit in the life insurance market. Change in term efficiency is a warning signal in the long-term business performance of life insurance firms. Economies of scale contribute to the business performance of life insurance firms. After being acquired by financial holdings companies or large firms, foreign companies showed marked improvement in efficiency. However, smaller firms did not experience the same uplift in efficiency when merging with these foreign companies.

Because dynamic DEA lacks carry-over, this study used return on assets as the carry-over between financial periods. This shows that firms place considerable emphasis on management of assets and liabilities in order to ensure future solvency. Most life insurance companies achieved optimal carry-over efficiency; in other words, the output (return on assets) of the previous quarter drives business performance in the subsequent quarter.

To summarize, Taiwan is a small economy and the life insurance industry in Taiwan are mature. Economies of scale contribute to the business performance of life insurance firms. Insurance companies acquired by financial holdings firms have become economies of scale, which has intensified market competition. The insurance market in Taiwan has evolved towards localization, making it difficult for new, foreign-owned players to enter the market. Small-to-medium life insurance firms should consider mergers with FHC or large firms, in order to expand their scale and improve their market share and competiveness. In the future the research can focus on the group of life insurance products.

\section{References}

Avkiran, N. K. (2015). An illustration of dynamic network DEA in commercial banking including robustness tests. Omega, 55, 141-150. http://dx.doi.org/10.1016/j.omega.2014.07.002

Barros, C. P., Nektarios, M., \& Assaf, A. (2010). Efficiency in the Greek Insurance Industry. European Journal of Operational Research, 205, 431-436. http://dx.doi.org/10.1016/j.ejor.2010.01.011

Castelli, L., Pesenti, R., \& Ukvich, W. (2004). DEA-like models for the efficiency evaluation of hierarchically structured units. European Journal of Operational Research 154, 465-476. http://dx.doi.org/10.1016/S0377-2217(03)00182-6

Charnes, A., Cooper, W. W., \& Rhodes, E. (1978). Measuring the Efficiency of Decision Making Uits. European Journal of Operational Research, 2, 429-444. http://dx.doi.org/10.1016/j.ejor.2010.01.011

Chen, H. Q., \& Hu, J. L. (2008). Environmental Effects and Statistical Noise-Adjusted Efficiency of Life Insurance Companies in Taiwan. Journal of Insurance Issues and Practices, 7(2), 189-206.

Cummins, J. D., \& Zi, H. (1998). Comparison of Frontier Efficiency Methods: An Application to the U.S. Life Insurance Industry. Journal of Productivity Analysis, 10(2), 131-152. http://dx.doi.org/10.1023/A:1026402922367

Cummins, J. D., Weiss, M. A., Xie, X., \& Zi, H. (2010). Economies of scope in financial services: A DEA efficiency analysis of the US insurance industry. Journal of Banking \& Finance, 34, 1525-1539. http://dx.doi.org/10.1016/j.jbankfin.2010.02.025

Färe, R., \& Grosskopf, S. (1994). Theory and Calculation of Productivity Indexes. In: Models and Measurement of Welfare and Inequality Springer, Berlin, Heidelberg, New York, 921-940. http://dx.doi.org/10.1007/978-3-642-79037-9_49

Fare, R., \& Grosskopf, S. (1996). Productivity and Intermediate Products: A Frontier Approach. Economics Letters 50, 65-70. http://dx.doi.org/10.1016/0165-1765(95)00729-6

Färe, R., \& Grosskopf, S. (1997). Intertemporal production frontiers: with dynamic DEA. Journal of the Operational Research Society, 48, 656-656. http://dx.doi.org/10.1057/palgrave.jors.2600779

Färe, R., Grosskopf, S., \& Whittaker, G. (2007). Network DEA,” In Modeling Data Irregularities and Structural Complexities in Data Envelopment Analysis, 209-240, Springer US.

Färe, R., Grosskopf, S., \& Whittaker, G. (2014). Network DEA II. In W. D. Cook and J. Zhu (eds.), Data Envelopment Analysis: A Handbook of Modeling Internal Structure and Network, 307-327, International Series in Operations Research \& Management Science 208, Springer Science+Business Media New York. http://dx.doi.org/10.1007/978-1-4899-8068-7_14

Färe, R., Grosskopf, S., Norris M., \& Zhang, Z. (1994). Productivity growth, technical progress, and efficiency change 
in industrialized countries. American Economic Review, 84, 66-83.

Färe, R., Grosskopf, S., Norris, M., \& Zhang, Z. (1994). Productivity Growth, Technical Progress, and Efficiency Changes in Industrialized Countries. American Economic Review, 84, 66-83.

Farrell, M. J. (1957). The Measurement of Productive Efficiency. Journal of the Royal Statistical Society, Series A, CXX, Part 3, 253-290. http://dx.doi.org/10.2307/2343100

Fukuyama, H. \& Weber, W. L. (2014). Measuring Japanese bank performance: a dynamic network DEA approach. Journal of Productivity Analysis, 1-16.

Fukuyama, H. (1997). Investigating Productive Efficiency and Productivity Changes of Japanese Life Insurance Companies. Pacific-Basin Finance Journal, 5, 481-509. http://dx.doi.org/10.1016/S0927-538X(97)00016-4

Homburg, C. (2001). Using data envelopment analysis to benchmark activities. International Journal of Production Economics 73, 51-58. http://dx.doi.org/10.1016/S0925-5273(01)00194-3

Hu, J. L., Chang, T. P., \& Zhu, X. H. (2014). A Comparative Study of Disaggregate Input Efficiency of Life Insurance Companies across the Taiwan Strait: An Application of the Stochastic Frontier Analysis. Soochow Journal of Economics and Business, 85, 41-62.

Hu, J. L., Sher, Y., \& Lin, F. L. (2012). Efficiency Analysis of Life Insurance Companies in Taiwan: A Two-Stage Data Envelopment Analysis. Journal of Insurance Issues and Practices, 11(1), 21-42.

Hu, X., Zhang, C., Hu, J. L., \& Zhu, N. (2009). Analyzing Efficiency in the Chinese Life Insurance Industry. Management Research News, 32, 905-920. http://dx.doi.org/10.1108/01409170910994123

Huang, T. H., Kao, T. L., Chiang, L. C., \& Liang, J. H. (2010). A Study of Technical Efficiency and Productivity Change on Taiwan's Life Insurance Companies with Quasi-fixed Inputs. Soochow Journal of Economics and Business, 68, 1-38.

Huang, X. N., \& Wu, G. H. (2001). Measurement of the Performance of the Life Insurance Industry in Taiwan. Journal of Management and Systems, 8, 401-420.

Kao, C., \& Hwang, S. (2008). Efficiency Decomposition in Two-stage Data Envelopment Analysis: An Application to Non-life Insurance Companies in Taiwan. European Journal of Operational Research ,185, 418-429. http://dx.doi.org/10.1016/j.ejor.2006.11.041

Klopp, G. A. (1985). The Analysis of the Efficiency of Production System with Multiple Inputs and Outputs. Ph. D. dissertation, University of Illinois, Industrial and System Engineering College, Chicago.

Liu, C. C. (1994). Evaluating the Operational Efficiency of Life Insurance Companies in Taiwan -Local Life Insurance Firms Comparing with International Life Insurance Firms. Taiwan Insurance Review, 37, 114-126.

Lu, Y. H., Wang, C. H., \& Lee, C. H. (2011). The Differences in the Technology Efficiency of Taiwan's Life Insurance Companies-The Application of the Metafrontier DEA Model. Journal of Economics and Management, 7(1), $73-100$.

Malmquist, S. (1953). Index numbers and indifference surfaces. Trabajos de Investigacion, 4, 209-242. http://dx.doi.org/10.1007/bf03006863

Pottier, S. W. (2011). Life insurer efficiency and state regulation: evidence of optimal firm behavior. Journal of Regulatory Economics, 39, 169-193. http://dx.doi.org/10.1007/s11149-010-9139-7

Seiford, L. M., \& Zhu, J. (1999). Profitability and Marketability of the Top 55 U.S. Commercial Banks. Management Science, 45, 1270-1288. http://dx.doi.org/10.1287/mnsc.45.9.1270

Sinha, R. P. (2015). A Dynamic DEA Model for Indian Life Insurance Companies. Global Business Review, 16(2), 1-12. http://dx.doi.org/10.1177/0972150914564418

Tone, K., \& Tsutsui, M. (2010). An epsilon-based measure of efficiency in DEA-A third pole of technical efficiency. European Journal of Operational Research, 207, 1554-1563. http://dx.doi.org/10.1016/j.ejor.2010.07.014

Tone, K. \& Tsutsui, M. (2010). Dynamic DEA: A slacks-based measure approach. Omega, 38(3/4), 145-156. http://dx.doi.org/10.1016/j.omega.2009.07.003

Tone, K. \& Tsutsui, M. (2014). Dynamic DEA with network structure: A slacks-based measure approach. Omega, 42(1), 124-131. http://dx.doi.org/10.1016/j.omega.2013.04.002

Tone, K., \& Tsutsui, M. (2009). Network DEA: A slacks-based measure approach. European Journal of Operational Research, 197, 243-252. http://dx.doi.org/10.1016/j.ejor.2008.05.027 
Tone, K., \& Tsutsui, M. (2010). Dynamic DEA: A slacks-based measure approach. Omega, 38(3/4), 145-156. http://dx.doi.org/10.1016/j.omega.2009.07.003

Wang, W. Y., Hao, C. J., \& Chen, Y. W. (2007). Measurement of Economic Efficiency in the Presence of Quasi-fixed Inputs: A DEA Application to the Life Insurance in Taiwan. presented at an academic conference of the Taiwan Risk and Insurance Association (TRIA).

Wu, D., Yang, Z., Vela, S., \& Liang, L. (2007). Simultaneous analysis of production and investment performance of Canadian life and health insurance companies using data envelopment analysis. Computers and Operations Research, 34, 180-198. http://dx.doi.org/10.1016/j.cor.2005.05.005

Xie, M. R. (2012). Discussion of Structural Changes in the Taiwanese Life Insurance Industry. "National Policy Foundation, research report.

Yang, Z. (2006). A two-stage DEA Model to Evaluate the Overall Performance of Canadian Life and Health Insurance Companies. Mathematical and Computer Modelling, 43, 910-919. http://dx.doi.org/10.1016/j.mcm.2005.12.011

\section{Copyrights}

Copyright for this article is retained by the author(s), with first publication rights granted to the journal.

This is an open-access article distributed under the terms and conditions of the Creative Commons Attribution license which permits unrestricted use, distribution, and reproduction in any medium, provided the original work is properly cited. 